\title{
Characteristics and prognostic factors for pain management in 152 patients with lung cancer
}

\author{
This article was published in the following Dove Press journal: \\ Patient Preference and Adherence \\ 15 April 2016 \\ Number of times this article has been viewed
}

\section{Lei Shi ${ }^{1, *}$ \\ Yumei Liu²,* \\ Hua $\mathrm{He}^{\prime}$ \\ Cong Wang' \\ Hongwei Li ${ }^{1}$ \\ Nanya Wang'}

'Cancer Center, The First Hospital of Jilin University, Changchun,

${ }^{2}$ Department of Hematology, Tianjin

Medical University General Hospital,

Tianjin, People's Republic of China

*These authors contributed equally to this work
Correspondence: Nanya Wang Cancer Center, The First Hospital of Jilin University, No 7I Xinmin Street, Changchun I3002I, People's Republic of China

$\mathrm{Tel}+86$ I58 $043026 I I$

Email nanyawang@yahoo.com
Objective: The objective of this study was to analyze the pain characteristics and factors influencing the outcome of pain control in patients with lung cancer having pain.

Methods: Pain characteristics, the effectiveness, and prognostic factors for pain control were analyzed in 152 patients with lung cancer having moderate or severe chronic pain admitted to Cancer Center of The First Hospital of Jilin University, People's Republic of China, between January 2012 and May 2013. Information about sex, age, pathological type, TNM stage, presence/absence of bone metastases, characteristics of pain, methods, and effectiveness of pain management was recorded.

Results: Patients with non-small-cell lung cancer and small-cell carcinoma accounted for 132/152 $(86.8 \%)$ and 20/152 (13.2\%) cases, respectively. Among them, moderate (72.4\%) or severe pain $(27.6 \%$ ) was reported in $73.7 \%$ of the cases at stage IV, chest or back pain was reported in $76.3 \%$ of the cases, and pain in other locations in the rest of the cases. Bone metastases were apparent in $44.1 \%$ of the patients. Neuropathic pain was noted in $46.7 \%$ of the patients, and frequent breakthrough pain was noted in $25.7 \%$ of the patients. High pain intensity was associated with frequent breakthrough pain. Pain was adequately controlled in $81.6 \%$ of the patients prescribed 3 days of analgesics. More patients reported a KPS higher than or equal to 80 after 3 days of analgesic treatment $(P<0.001)$. Severe pain, frequent breakthrough pain, and presence of bone metastases were independent risk factors for poor pain control. Severe pain, frequent breakthrough pain, or neuropathic pain in the patients using opioids required higher doses of analgesic for pain control. Opioids plus nonsteroidal anti-inflammatory drugs offered better pain control than opioids alone.

Conclusion: High pain intensity is associated with frequent breakthrough pain in patients with lung cancer, which can be largely controlled with analgesics. Severe pain, frequent breakthrough pain, presence of bone metastases, and neuropathic pain are predictors of refractory pain.

Keywords: lung cancer, chronic pain, pain intensity, analgesic effects

\section{Introduction}

The World Health Organization statistics indicated that $\sim 2$ million people suffer pain everyday worldwide. Pain is one of the most common symptoms in patients with malignant tumor, substantially affecting patients' quality of life. Approximately $25 \%$ of newly diagnosed patients report pain and $\sim 60 \%-80 \%$ of patients with advanced cancer have chronic pain, one-third of them are categorized as severe. ${ }^{1,2}$ Lung cancer is the most common malignant tumor worldwide, ${ }^{3}$ with an average survival of $<1$ year in advanced patients making palliative care an especially important consideration. The incidence of pain is $47 \%$ in all patients with lung cancer, and $76 \%$ in those in palliative care. ${ }^{4}$

Although most patients achieve adequate pain control, those with more complex pain syndromes require intense and complex analgesic schedules. ${ }^{5}$ Pain intensity is a key element of prognostication and management of cancer pain, ${ }^{6-8}$ and greater 
awareness of the prognostic factors associated with poor pain control would guide specific and appropriate treatment strategies. The Edmonton Classification System for Cancer Pain has been extensively studied ${ }^{5,7,9}$ and indicates that incident pain (breakthrough pain), neuropathic pain, psychological distress, addiction, and cognitive function are predictors of pain control..$^{6,7,9}$ However, there is no consensus generally on the prognostic factors for pain control or specifically on the pain characteristics in patients with lung cancer having moderate or severe chronic pain. Therefore, this study analyzed pain characteristics and prognostic data from 152 patients with lung cancer having moderate or severe chronic pain at the Cancer Center in the Bethune First Hospital of Jilin University, People's Republic of China, between January 1, 2012, and May 31, 2013.

\section{Methods}

This retrospective study was approved by ethics committee of the First Hospital of Jilin University. Data including host characteristics (sex and age), disease factors (pathological type, tumor-node-metastasis [TNM] stage, and presence of bone metastases), pain factors (pain intensity, locations, causes, mechanisms, breakthrough pain, and its frequency), treatment (final opioid doses, drug ladder, medication route, and combination with nonsteroidal anti-inflammatory drugs [NSAIDs]), and the Karnofsky Performance Status (KPS) were analyzed from 152 patients with pathologically diagnosed lung cancer reporting moderate or severe chronic pain at the Cancer Center of The First Hospital of Jilin University, People's Republic of China, between January 1, 2012, and May 31, 2013. Pain control was evaluated after 3 days of analgesia in all the patients. For the patients medicated with potent opioids, the final median opioid doses were transformed into morphine equivalent daily dose (MEDD) prior to analysis, while for those using weak opioids, the doses were not transformed.

All patients were treated in accordance with the National Comprehensive Cancer Network (NCCN) cancer pain guidelines for adults. ${ }^{10}$ Patients rated their pain intensity daily using the Numeric Rating Scale, ranging from 0 (no pain) to 10 (worst possible pain) with ratings of $1-3$ corresponding to mild pain, 4-6 moderate pain, and 7-10 severe pain. For the purpose of this study, stable pain control was defined as a Numeric Rating Scale rating of $\leq 3 / 10$ or patients receiving $<3$ breakthrough analgesic doses/d.

Univariate and multivariate logistic regression analyses using SPSS 17.0 (SPSS Inc., Chicago, IL, USA) were used to identify the associations between the variables and the pain control after 3 days of analgesia. As the sample distribution was not normal, nonparametric Kruskal-Wallis and
Mann-Whitney tests examined differences in pain intensity and final median opioid doses. The chi-square test was used to compare the frequency data. Statistical significance was set at $P<0.05$ (two tailed).

\section{Results}

The demographic and clinical characteristics of the 152 patients included in the study are listed in Table 1 . The male/female

Table I Patients' demographics and clinical characteristics ( $\mathrm{N}=\mathrm{I52})$

\begin{tabular}{|c|c|}
\hline Characteristics & $\mathbf{N}=152(\%)$ \\
\hline \multicolumn{2}{|l|}{ Demographics } \\
\hline \multicolumn{2}{|l|}{ Sex } \\
\hline Male & $99(65.1)$ \\
\hline Female & $53(34.9)$ \\
\hline Age, median, range (years) & $58,32-81$ \\
\hline$<60$ & $87(57.2)$ \\
\hline$\geq 60$ & $65(42.8)$ \\
\hline \multicolumn{2}{|l|}{ Clinical characteristics } \\
\hline \multicolumn{2}{|l|}{ Pathological type } \\
\hline Non-small-cell & $132(86.8)$ \\
\hline Small cell & $20(13.2)$ \\
\hline \multicolumn{2}{|l|}{ Pain intensity } \\
\hline Moderate & $110(72.4)$ \\
\hline Severe & $42(27.6)$ \\
\hline \multicolumn{2}{|l|}{ TNM stage } \\
\hline $\mathrm{I} / \mathrm{II} / \mathrm{II}$ & $26(17.1)$ \\
\hline IV & $112(73.7)$ \\
\hline Unknown & $14(9.2)$ \\
\hline \multicolumn{2}{|l|}{ Causes of pain } \\
\hline Nontumor invasion & $12(7.9)$ \\
\hline Tumor invasion & $140(92.1)$ \\
\hline \multicolumn{2}{|l|}{ Bone metastases } \\
\hline Without & $85(55.9)$ \\
\hline With & $67(44.1)$ \\
\hline \multicolumn{2}{|l|}{ Locations of pain } \\
\hline Chest or back & $116(76.3)$ \\
\hline Other parts & $36(23.7)$ \\
\hline \multicolumn{2}{|l|}{ Frequent breakthrough pain } \\
\hline Without & II $3(74.3)$ \\
\hline With & $39(25.7)$ \\
\hline \multicolumn{2}{|l|}{ Neuropathic pain } \\
\hline Without & 81 (53.3) \\
\hline With & 7I (46.7) \\
\hline \multicolumn{2}{|l|}{ Analgesic treatment } \\
\hline \multicolumn{2}{|l|}{ Drug ladder } \\
\hline Weak opioids & $69(45.4)$ \\
\hline Strong opioids & $83(54.6)$ \\
\hline \multicolumn{2}{|l|}{ Combined with NSAIDs } \\
\hline Without & $107(70.4)$ \\
\hline With & $45(29.6)$ \\
\hline \multicolumn{2}{|l|}{ Route of administration } \\
\hline Oral & 147 (96.7) \\
\hline Injection & $2(1.3)$ \\
\hline Patch & $3(2.0)$ \\
\hline \multicolumn{2}{|l|}{ Pain control } \\
\hline Good & $124(81.6)$ \\
\hline Poor & $28(18.4)$ \\
\hline
\end{tabular}

Abbreviations: NSAIDs, nonsteroidal anti-inflammatory drugs; TNM, tumornode-metastasis. 
ratio was $1.87: 1$, and age ranged from 32 to 81 years, with a median age of 58 years. There were 65 patients $(42.8 \%)$ older than 60 years and $87(57.2 \%)$ younger than 60 years. Nonsmall-cell lung cancer accounted for 132 (86.8\%) cases and $20(13.2 \%)$ were small-cell lung cancer. A total of 26 patients $(17.1 \%)$ were in stage I, II, or III; 112 patients $(73.7 \%)$ were in stage IV; and the stage was unknown for 14 patients $(9.2 \%)$. Bone metastases were apparent in 67 patients (44.1\%). Most patients exhibited moderate pain (72.4\%), with the remainder $(27.6 \%)$ classified as having severe pain. The majority of patients reported chest or back pain $(76.3 \%)$, while pain in other parts accounted for just $23.7 \%$. The main cause of pain was tumor invasion $(92.1 \%), 71$ patients $(46.7 \%)$ had neuropathic pain and 39 patients $(25.7 \%)$ had frequent breakthrough pain (more than three times per day).

The associations between the pain intensity and the variables of sex, age, pathological type, TNM stage, bone metastases, locations, causes, mechanisms of pain, and frequent breakthrough pain are shown in Table 2. The frequent breakthrough pain was associated with high pain intensity

Table 2 Comparison on pain intensity stratified by demographics and clinical characteristics $(\mathrm{N}=\mid 52)$

\begin{tabular}{|c|c|c|}
\hline Characteristics & $\begin{array}{l}\text { NRS score, } \\
\text { median (IQR) }\end{array}$ & $P$-value ${ }^{a}$ \\
\hline Sex & & 0.574 \\
\hline Male & $6(4-7)$ & \\
\hline Female & $6(5-6)$ & \\
\hline Age & & 0.698 \\
\hline$<60$ years & $6(4-7)$ & \\
\hline$\geq 60$ years & $6(5-7)$ & \\
\hline Pathological type & & 0.955 \\
\hline Non-small-cell & $6(5-7)$ & \\
\hline Small cell & $6(4-7)$ & \\
\hline Bone metastases & & 0.406 \\
\hline Without & $6(4-7)$ & \\
\hline With & $6(5-7)$ & \\
\hline Causes of pain & & 0.063 \\
\hline Nontumor invasion & $5(4-6)$ & \\
\hline Tumor invasion & $6(5-7)$ & \\
\hline Neuropathic pain & & 0.144 \\
\hline Without & $6(4-7)$ & \\
\hline With & $6(5-7)$ & \\
\hline Locations of pain & & 0.500 \\
\hline Chest or back & $6(4-7)$ & \\
\hline Other parts & $6(5-7)$ & \\
\hline Frequent breakthrough pain & & $<0.001$ \\
\hline Without & $5(4-6)$ & \\
\hline With & $6(6-8)$ & \\
\hline TNM stage & & 0.664 \\
\hline $\mid \mathrm{I} / \mathrm{II} / \mathrm{II}$ & $6(4-7)$ & \\
\hline IV & $6(5-7)$ & \\
\hline Unknown & $5(4-6)$ & \\
\hline
\end{tabular}

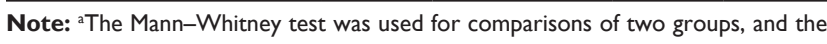
Kruskal-Wallis test was used for comparisons of more than two groups.

Abbreviations: NRS, Numerical Rating Scale; IQR, interquartile range; TNM, tumor-node-metastasis.
$(P<0.001)$, while the other eight variables were not significantly associated with pain intensity $(P>0.05)$.

All 152 patients accepted analgesic treatment, and 124 (81.6\%) achieved adequate pain control after 3 days but pain control was poor in $28(18.4 \%)$. As shown in Table 1, weak opioids were used by 69 patients (45.4\%) and 83 (54.6\%) used potent opioids. There were 147 patients (96.7\%) taking analgesics by oral administration, two (1.3\%) by injection, and three $(2.0 \%)$ by transdermal patches. Furthermore, 45 patients $(29.6 \%)$ were taking NSAIDs in addition to opioids. More patients reported a KPS $\geq 80$ after 3 days of analgesic treatment $(P<0.001)$ (Table 3 ).

The associations between the pain control after 3 days of analgesic treatment and the ten variables are summarized in Table 4. Both univariate and multivariate logistic regression analyses showed that bone metastases (univariate: odds ratio $[\mathrm{OR}]=3.343,95 \%$ confidence interval [CI]: 1.398-7.991, $P=0.007$; multivariate: $\mathrm{OR}=3.583,95 \% \mathrm{CI}: 1.136-11.297$, $P=0.029$ ), severe pain (univariate: $\mathrm{OR}=4.415,95 \% \mathrm{CI}$ : 1.760-9.761, $P=0.001$; multivariate: $\mathrm{OR}=3.878,95 \% \mathrm{CI}$ : $1.510-9.960, P=0.005$ ), and frequent breakthrough pain (univariate: $\mathrm{OR}=3.267,95 \% \mathrm{CI}: 1.383-7.715, P=0.007$; multivariate: $\mathrm{OR}=2.798,95 \%$ CI: $1.033-7.576, P=0.043$ ) were significantly associated with poor pain control. Sex, age, pathological type, TNM stage, locations of pain, causes, and mechanisms of pain were not significantly associated with pain control $(P>0.05)$.

The final opioid doses of the 83 patients using potent opioids were transformed into MEDD prior to analysis. The associations between the final MEDD and the ten variables are shown in Table 5. Significantly higher opioid doses were used in patients with severe pain $(P=0.015)$, neuropathic pain ( $P=0.020)$, and frequent breakthrough pain $(P=0.016)$; however, there were no significant differences in final MEDD in patients of different sex, age, pathological type, TNM stage, locations, and causes of pain or in patients with or without bone metastases $(P>0.05)$.

As shown in Table 6, opioids combined with NSAIDs achieved better pain control after 3 days of analgesic treatment than opioids without NSAIDs $(P=0.001)$.

Table 3 Comparison of KPS before and after analgesic treatment $(\mathrm{N}=152)$

\begin{tabular}{lllll}
\hline $\begin{array}{l}\text { KPS before } \\
\text { treatment }\end{array}$ & \multicolumn{2}{l}{ KPS after treatment } & Total (\%) & P-value $^{\mathbf{a}}$ \\
\cline { 2 - 3 } & $\geq \mathbf{8 0}$ & $<\mathbf{8 0}$ & & \\
\hline$\geq 80$ & 98 & 3 & I0I $(66.4)$ & $<0.00$ I \\
$<80$ & 16 & 35 & 5 I $(33.6)$ & \\
Total (\%) & II4 (75.0) & $38(25.0)$ & I52 (100) & \\
\hline
\end{tabular}

Note: aMcNemar's test.

Abbreviation: KPS, Karnofsky Performance Status. 
Table 4 Odd ratios of pain poor control after analgesic treatment $(\mathrm{N}=\mathrm{I52})$

\begin{tabular}{|c|c|c|c|c|}
\hline \multirow[t]{2}{*}{ Variables } & \multicolumn{2}{|l|}{ Univariate } & \multicolumn{2}{|l|}{ Multivariate } \\
\hline & OR $(95 \% \mathrm{Cl})$ & $P$-value ${ }^{a}$ & OR $(95 \% \mathrm{Cl})$ & $P$-value ${ }^{a}$ \\
\hline \multicolumn{5}{|l|}{ Sex } \\
\hline Female vs male & $0.702(0.286-1.724)$ & 0.440 & $0.667(0.246-1.809)$ & 0.426 \\
\hline \multicolumn{5}{|l|}{ Age } \\
\hline$\geq 60$ years vs $<60$ years & $1.005(0.439-2.301)$ & 0.991 & $0.984(0.388-2.492)$ & 0.973 \\
\hline \multicolumn{5}{|l|}{ Pathological type } \\
\hline Small vs non-small-cell & I.I 25 (0.345-3.667) & 0.845 & $1.594(0.418-6.084)$ & 0.495 \\
\hline \multicolumn{5}{|l|}{ TNM stage } \\
\hline IV vs I/II/III & 2.091 (0.578-7.558) & 0.261 & $1.033(0.185-5.759)$ & 0.971 \\
\hline Unknown vs I/II/III & $0.590(0.056-6.266)$ & 0.661 & $0.592(0.044-7.997)$ & 0.693 \\
\hline \multicolumn{5}{|l|}{ Bone metastases } \\
\hline With vs without & 3.343 (I.398-7.99I) & 0.007 & $3.583(1.136-\mid 1.297)$ & 0.029 \\
\hline \multicolumn{5}{|l|}{ Pain intensity } \\
\hline Severe vs moderate & $4.4 I 5(I .760-9.76 I)$ & 0.001 & $3.878(1.510-9.960)$ & 0.005 \\
\hline \multicolumn{5}{|l|}{ Locations of pain } \\
\hline Other vs chest or back & $2.094(0.864-5.077)$ & 0.102 & $1.012(0.332-3.080)$ & 0.984 \\
\hline \multicolumn{5}{|l|}{ Tumor invasion } \\
\hline Yes vs no & $2.628(0.325-21.244)$ & 0.365 & $0.769(0.067-8.845)$ & 0.833 \\
\hline \multicolumn{5}{|l|}{ Neuropathic pain } \\
\hline With vs without & I.673 (0.73I-3.829) & 0.223 & $1.339(0.503-3.564)$ & 0.558 \\
\hline \multicolumn{5}{|l|}{ Frequent breakthrough pain } \\
\hline With vs without & 3.267 (1.383-7.7I5) & 0.007 & $2.798(1.033-7.576)$ & 0.043 \\
\hline
\end{tabular}

Note: aLogistic regression analyses were performed.

Abbreviations: OR, odds ratio; TNM, tumor-node-metastasis; $\mathrm{Cl}$, confidence interval.

\section{Discussion}

Chronic cancer pain seriously affects patients' quality of life, and pain control remains one of the main treatment obstacles. Lung cancer has the highest incidence of all malignancies and is commonly associated with pain. Since the average survival of patients with advanced lung cancer is $<1$ year, analgesia can have a significant impact on the quality of life. Characterizing the aspects of pain associated with lung cancer and the prognostic factors associated with pain management would provide valuable guidance for clinical analgesic treatment. However, there is currently no consensus on these parameters, and the evidence-based studies published to date are insufficient to draw firm conclusions. This study retrospectively analyzed the pain characteristics of 152 patients with lung cancer having moderate or severe chronic cancer pain and identified factors that may predict the outcome of analgesic treatment and could be used to inform clinical decision making.

Patient demographic statistics indicate that the number of male patients with lung cancer is approximately twice the number of female patients. Although the peak age for lung cancer diagnosis is 60-79 years old, in our study, elderly patients (aged 60 years or older) with moderate or severe pain reported it less frequently than the younger patients (aged $<60$ years) $(42.8 \%$ vs $57.2 \%)$. This may be due to the different tolerances to pain in patients of different ages, which is supported by Gagliese et al, ${ }^{11}$ who found that young patients were more sensitive to pain. ${ }^{11}$ Additionally, younger patients may be less tolerant of pain, impacting on their quality of life, while elderly patients may think pain is an inevitable part of cancer, and thus bear that pain untreated over time. Differences in pain perception between these two groups may lead to differences in pain intensity and different treatment outcomes.

In this study, approximately three-quarters of the patients were with advanced lung cancer, which is in accordance with foreign study. ${ }^{4}$ Non-small-cell lung cancer accounted for $86.8 \%$ of the cases, which is concordant with its known high incidence. Patients with moderate pain accounted for $72.4 \%$ of the total, and those with severe pain accounted for $27.6 \%$. In approximately three-quarters of patients, the location of pain was the chest or back, with other parts accounting for approximately one-quarter. In most patients, the pain was caused by tumor invasion and metastases $(92.1 \%)$, while their pain was due to other causes in a small proportion of cases. Approximately half of the patients had bone metastases, approximately half had neuropathic pain, and approximately one-quarter reported frequent breakthrough pain. 
Table 5 Comparison on final MEDD of patients using strong opioids stratified by demographics and clinical characteristics $(\mathrm{n}=83)$

\begin{tabular}{|c|c|c|}
\hline \multirow[t]{2}{*}{ Characteristics } & \multicolumn{2}{|l|}{ MEDD } \\
\hline & Median (IQR) & $P$-value ${ }^{a}$ \\
\hline Sex & & 0.534 \\
\hline Male & $60(40-80)$ & \\
\hline Female & $80(40-80)$ & \\
\hline Age & & 0.566 \\
\hline$<60$ years & $60(40-80)$ & \\
\hline$\geq 60$ years & $60(40-80)$ & \\
\hline Pathological type & & 0.217 \\
\hline Non-small-cell & $60(40-80)$ & \\
\hline Small cell & $60(40-80)$ & \\
\hline Bone metastases & & 0.413 \\
\hline Without & $60(40-80)$ & \\
\hline With & $80(40-80)$ & \\
\hline Causes of pain & & 0.990 \\
\hline Nontumor invasion & $80(20-80)$ & \\
\hline Tumor invasion & $60(40-80)$ & \\
\hline Neuropathic pain & & 0.020 \\
\hline Without & $60(20-80)$ & \\
\hline With & $80(60-80)$ & \\
\hline Pain intensity & & 0.015 \\
\hline Moderate & $60(40-80)$ & \\
\hline Severe & $80(50-120)$ & \\
\hline Locations of pain & & 0.486 \\
\hline Chest or back & $60(40-80)$ & \\
\hline Other parts & $80(40-80)$ & \\
\hline Frequent breakthrough pain & & 0.016 \\
\hline Without & $60(40-80)$ & \\
\hline With & $80(45-120)$ & \\
\hline TNM stage & & 0.621 \\
\hline $\mathrm{I} / \mathrm{II} / \mathrm{II}$ & $60(40-80)$ & \\
\hline IV & $65(40-80)$ & \\
\hline Unknown & $50(20-80)$ & \\
\hline
\end{tabular}

Note: aThe Mann-Whitney test was used for comparisons of two groups, and the Kruskal-Wallis test was used for comparisons of more than two groups.

Abbreviations: MEDD, morphine equivalent daily dose; IQR, interquartile range; TNM, tumor-node-metastasis.

This study showed that high pain intensity was associated with frequent breakthrough pain, which is in line with previous studies. ${ }^{12}$ Thus, reducing the frequency of breakthrough pain may lower the mean pain intensity, giving better pain management. In this study, we did not detect any associations between the pain intensity and the other variables.

Table 6 Pain control of patients with opioids combined with NSAIDs or opioids only ( $\mathrm{N}=152)$

\begin{tabular}{llll}
\hline Combined with & \multicolumn{2}{l}{ Pain control } & P-value $^{\text {a }}$ \\
\cline { 2 - 3 } NSAIDs & Good & Poor & \\
\hline Yes & 44 & 1 & 0.001 \\
No & 80 & 27 & \\
\hline
\end{tabular}

Note: a Chi-square test.

Abbreviation: NSAIDs, nonsteroidal anti-inflammatory drugs.
After priority was given to opioid analgesia for 3 days, $81.6 \%$ of patients achieved adequate pain control, and more patients reported a KPS $\geq 80$, suggesting analgesia can improve patients' quality of life. Most patients (54.6\%) were given potent opioids, mainly by the oral route $(96.7 \%)$, which is consistent with the NCCN guidelines. ${ }^{10}$

In this study, logistic regression analysis showed that severe pain, frequent breakthrough pain, and presence of bone metastases were independent risk factors for poor pain control after 3 days of analgesic treatment. Additionally, analysis of patients using potent opioids showed that high final opioid doses were associated with severe pain, neuropathic pain, and frequent breakthrough pain. Therefore, these factors may lead to difficulty in managing pain and poor pain control. Similar to previous studies, ${ }^{7,9}$ patients with more complex pain syndromes such as neuropathic and breakthrough pain, of moderate or severe pain intensity, may require complex analgesic strategies to achieve adequate pain control. Factors that may influence the outcome of pain management include host factors (eg, age, sex, and genetics), disease factors (eg, cancer type and stage), pain factors (eg, intensity, causes, and mechanisms), and among others..$^{13}$ In this study, sex, age, pathological type, TNM stage, locations, and causes of pain were not significantly associated with pain control.

Pain intensity plays a key role in the assessment and management of cancer pain, it not only guides clinical decision making but it is also an important prognostic factor for predicting complex pain. ${ }^{6,14}$ Fainsinger et $\mathrm{al}^{7}$ published an international multicenter study showing that higher pain intensity was associated with greater time taken to achieve stable pain control, as well as more adjuvant therapy, and higher final opioid doses. Kaasa et $a l^{8}$ summarized previous research results and pointed out that severe pain was more complex and refractory than moderate pain.

Breakthrough pain is considered to be a transient exacerbation of pain that occurs either spontaneously or in relation to a specific predictable or unpredictable trigger, despite relatively stable and adequately controlled background pain. ${ }^{15}$ Most patients with cancer pain $(63 \%)$ suffer from breakthrough pain, which is usually severe pain, and several studies have recognized this breakthrough pain as refractory pain. ${ }^{7}$ Fainsinger et $\mathrm{al}^{7}$ showed that median final opioid dose required to achieve stable pain control in patients with breakthrough pain was $60 \mathrm{mg}$, while it was $32 \mathrm{mg}$ in patients without breakthrough pain. In that study, breakthrough pain was also associated with greater time and more adjuvant therapy to reach stable pain control. 
Neuropathic pain is due to peripheral or central nervous system injury, leading to pain nerve fibers or pain centers producing abnormal nerve impulses. Previous studies have regarded neuropathic pain as a refractory pain index. ${ }^{7,8}$ In a study by Fainsinger et $a 1,{ }^{7}$ the median final opioid dose required to achieve stable pain control in patients with nociceptive pain was $30 \mathrm{mg}$, while it was $100 \mathrm{mg}$ in patients with neuropathic pain. Coadministration of tricyclic antidepressants and anticonvulsants can assist in the management of neuropathic pain. For intractable neuropathic pain, interventional therapies such as nerve blocks or nerve radiofrequency ablation can be effective treatments.

Bone metastases pain (hereafter referred to as bone pain) often has characteristics associated with inflammatory pain and neuropathic pain, and it is more complex than other kinds of pain, so opioids alone often do not provide sufficient analgesia. ${ }^{16}$ In animal experiments, three to ten times the opioid dose required to treat inflammatory pain was required to alleviate bone pain. ${ }^{17}$ In addition, bone metastases are the main cause of somatic breakthrough pain, and the latter is refractory. Analgesia combined with radiotherapy and bisphosphonate can effectively alleviate bone pain. ${ }^{18}$

Combining opioids with NSAIDs led to better pain control in $29.6 \%$ patients on this treatment protocol. This is consistent with Mercadante and Giarratano's study ${ }^{19}$ that analyzed studies published from 2001 to 2011 investigating NSAIDs combined with opioids and concluded that combining NSAIDs with opioids can facilitate better and more rapid control of pain.

There are other relevant prognostic factors for pain management in patients with lung cancer having moderate or severe chronic pain, such as genetic factors, psychological factors, and among others. Genetic studies suggest that single-nucleotide polymorphisms in the opioid receptor gene, ${ }^{20,21}$ catecholamine$O$-methyltransferase polymorphisms, ${ }^{22}$ and the activity of cytochrome $\mathrm{P} 450$ enzymes $^{23}$ can affect the outcome of analgesic treatment. Psychological distress can also hinder effective analgesic treatment, extending the time required to achieve stable pain control and necessitating more adjuvant treatment and drugs to control pain. ${ }^{7,9}$ With regard to studies investigating prognostic factors for pain management in patients with lung cancer pain, we need to increase sample sizes, extend observing times, refine the clinical data, and include more potential prognostic factors in the analysis, in order to obtain more significant data and provide a better basis for clinical practice.

This study provides important data that highlight some prognostic factor for poor pain management that should be taken into consideration when planning analgesia.

\section{Acknowledgments}

The authors would like to thank The First Hospital of Jilin University for technical assistance. This work was supported by a grant from the training program for young teachers of Jilin University, People's Republic of China (No 2008162). This research was presented as an abstract at the 2015 World Congress of Psycho-Oncology, held from July 28 to August 1, 2015, at Washington, DC, USA, and the abstract has been published in Psycho-Oncology, Volume 24, Special Issue.

\section{Disclosure}

The authors report no conflicts of interest in this work.

\section{References}

1. van den Beuken-van Everdingen MH, de Rijke JM, Kessels AG, Schouten HC, van Kleef M, Patijn J. Prevalence of pain in patients with cancer: a systematic review of the past 40 years. Ann Oncol. 2007;18(9): 1437-1449.

2. Costantini M, Ripamonti C, Beccaro M, et al. Prevalence, distress, management, and relief of pain during the last 3 months of cancer patients' life. Results of an Italian mortality follow-back survey. Ann Oncol. 2009;20(4):729-735.

3. Dresler $\mathrm{C}$. The changing epidemic of lung cancer and occupational and environmental risk factors. Thorac Surg Clin. 2013;23(2): 113-122.

4. Potter J, Higginson IJ. Pain experienced by lung cancer patients: a review of prevalence, causes and pathophysiology. Lung Cancer. 2004;43(3):247-257.

5. Fainsinger RL, Nekolaichuk CL. Cancer pain assessment - can we predict the need for specialist input? Eur J Cancer. 2008;44(8): 1072-1077.

6. Fainsinger RL, Fairchild A, Nekolaichuk C, Lawlor P, Lowe S, Hanson J. Is pain intensity a predictor of the complexity of cancer pain management? J Clin Oncol. 2009;27(4):585-590.

7. Fainsinger RL, Nekolaichuk C, Lawlor P, et al. An international multicentre validation study of a pain classification system for cancer patients. Eur J Cancer. 2010;46(16):2896-2904.

8. Kaasa S, Apolone G, Klepstad P, et al. Expert conference on cancer pain assessment and classification - the need for international consensus: working proposals on international standards. BMJ Support Palliat Care. 2011;1(3):281-287.

9. Fainsinger RL, Nekolaichuk CL, Lawlor PG, Neumann CM, Hanson J, Vigano A. A multicenter study of the revised Edmonton staging system for classifying cancer pain in advanced cancer patients. J Pain Symptom Manage. 2005;29(3):224-237.

10. Swarm R, Abernethy AP, Anghelescu DL, et al; National Comprehensive Cancer Network. Adult cancer pain. J Natl Compr Canc Netw. 2010;8(9):1046-1086.

11. Gagliese L, Jovellanos M, Zimmermann C, Shobbrook C, Warr D, Rodin G. Age-related patterns in adaptation to cancer pain: a mixedmethod study. Pain Med. 2009;10(6):1050-1061.

12. Porta-Sales J. Breakthrough cancer pain and current treatment options [J]. Euro J Pain Suppl. 2010;4(3):181-185.

13. Knudsen AK, Brunelli C, Klepstad P, et al. Which domains should be included in a cancer pain classification system? Analyses of longitudinal data. Pain. 2012;153(3):696-703.

14. Dworkin RH, Turk DC, Farrar JT, et al; IMMPACT. Core outcome measures for chronic pain clinical trials: IMMPACT recommendations. Pain. 2005;113(1-2):9-19. 
15. Davies AN, Dickman A, Reid C, et al; Science Committee of the Association for Palliative Medicine of Great, and Ireland. The management of cancer-related breakthrough pain: recommendations of a task group of the Science Committee of the Association for Palliative Medicine of Great Britain and Ireland. Eur J Pain. 2009;13(4):331-338.

16. Shaiova L. Difficult pain syndromes: bone pain, visceral pain, and neuropathic pain. Cancer J. 2006;12(5):330-340.

17. Luger NM, Mach DB, Sevcik MA, Mantyh PW. Bone cancer pain: from model to mechanism to therapy. J Pain Symptom Manage. 2005;29(5 suppl):S32-S46.

18. Ripamonti CI, Santini D, Maranzano E, et al; E.G.W. Group. Management of cancer pain: ESMO Clinical Practice Guidelines. Ann Oncol. 2012;23(suppl 7):vii139-vii154.

19. Mercadante S, Giarratano A. The long and winding road of non steroidal anti-inflammatory drugs and paracetamol in cancer pain management: a critical review. Crit Rev Oncol Hematol. 2013;87(2):140-145.
20. Chou WY, Wang CH, Liu PH, Liu CC, Tseng CC, Jawan B. Human opioid receptor A118G polymorphism affects intravenous patientcontrolled analgesia morphine consumption after total abdominal hysterectomy. Anesthesiology. 2006;105(2):334-337.

21. Hayashida M, Nagashima M, Satoh Y, et al. Analgesic requirements after major abdominal surgery are associated with OPRM1 gene polymorphism genotype and haplotype. Pharmacogenomics. 2008;9(11):1605-1616.

22. Rakvag TT, Ross JR, Sato H, Skorpen F, Kaasa S, Klepstad P. Genetic variation in the catechol-O-methyltransferase (COMT) gene and morphine requirements in cancer patients with pain. Mol Pain. 2008;4:64.

23. Stamer UM, Stuber F. Codeine and tramadol analgesic efficacy and respiratory effects are influenced by CYP2D6 genotype. Anaesthesia. 2007;62(12):1294-1295; author reply 1295-1296.

\section{Publish your work in this journal}

Patient Preference and Adherence is an international, peer-reviewed, open access journal that focuses on the growing importance of patient preference and adherence throughout the therapeutic continuum. Patient satisfaction, acceptability, quality of life, compliance, persistence and their role in developing new therapeutic modalities and compounds to optimize clinical outcomes for existing disease states are major areas of interest for the journal. This journal has been accepted for indexing on PubMed Central. The manuscript management system is completely online and includes a very quick and fair peer-review system, which is all easy to use. Visit http://www. dovepress.com/testimonials.php to read real quotes from published authors.

Submit your manuscript here: http://www.dovepress.com/patient-preference-and-adherence-journal 